\title{
Therapeutic angiogenesis by stem cell: new hope for the ischemic limbs
}

\author{
Mohiuddin $\mathrm{AKM}^{1}$, Anwar $\mathrm{R}^{2}$, Lewis $\mathrm{P}^{3}$, Sadiq $\mathrm{BA}^{4}$
}

\begin{abstract}
Critical limb ischemia in an intractable condition associated with high level of amputation, leading to low quality of life increase morbidity and mortality. It is often not treated by standard therapeutic modalities. Neoangiogenesis has been proposed as a novel method of treatment of such patients. Vascular Endothelial Growth Factor (VEGF) and Cytokine Fibroblast growth Factor (FGF1) have been shown to elicit neoangiogesis. Stem cells are progenitor cells which can differentiate in vivo into different type of cells. Collateral vessel formation after stem cell therapy.
\end{abstract}

A case of 50 years old male, diabetic, hypertensive with dry gangrene of tip of left ring finger was treated with stem cell therapy after proper counseling. He received the therapy in the form of SVF (Stromal Vascular Fraction) from adipose tissue by local injection in the territory of the affected vessels. Following monitoring parameters were reported, improved wound status, local temperature change, oxygen saturation change in the ischemic zone. Outcome of stem cell therapy in this case including the rest pain disappeared at 14 days and the finger becomes warmed by $5^{\circ} \mathrm{C}$ in 3 weeks. The gangrenous area healed in 3 months. Amputation was averted.

Angiogenesis is a complex process leading to new blood vessels formation. Mesenchymal stem cells (MSCs) are a type of adult stem cell which has an immunomodulatory effect. Stem cell therapy has been used to improve limb Vascularity. Stem Cells are likely to be an important modality to treat critical limb ischemia.

CBMJ 2019 July: vol. 08 no. 02 P: 40-46

Key words: arterial occlusion, stem cells, acute limb ischemia, Angiogenesis

\section{Introduction}

With the development of society and improvement of living standards, ischemic diseases have become a leading cause of disabilities and deaths in humans. Ischemic diseases are characterized by a reduction of blood supply with limited oxygen transfer and nutrient uptake. Thus, angiogenesis and blood supply reconstruction are key for treatment of ischemic diseases. Current clinical treatments primarily involve medical therapy (thrombolytic drugs and vasodilator drugs) and surgery. ${ }^{1,2}$ However, it remains difficult to achieve the purpose of vascular remodeling using either drugs or surgery., Inspired by the fact that the body undergoes natural angiogenesis in response to an insufficient blood supply, scientists have learned to enhance the efficiency of angiogenesis as a treatment strategy. The concept of therapeutic angiogenesis involves introducing an agent to promote the growth of new blood vessels in ischemic tissue. Stem cell therapy is a technology that has shown great prospects for ischemic diseases. ${ }^{5,6}$

Indeed, stem cells have been used in animal models and clinical trials to treat various ischemic diseases. However, as transplantation of stem cells continues to be limited by ethical issues, tumorigenicity, and immune rejection, such therapies are not widely available in the clinic.

Recent studies have found that stem cell supernatants can promote repair of damaged tissue. ${ }^{7,8}$ Accordingly, researchers began to focus on the exocrine

1. Dr. A.K.M. Mohiuddin, Orthopedic \& Regenerative Medicine Specialist

2. Dr. Raihan Anwar, Plastic Surgeon \& Regenerative Medicine Specialist

3. Dr. Peter Lewis, Regenerative Medicine Specialist

4. Dr. B.A. Sadiq, Regenerative Medicine Specialist

Address of correspondence:

E mail:mmc29pintu@gmail.com Mobile: 01711182127 
function of stem cells. Extracellular vesicles (EVs), which are secreted from cells, have been discovered for more than 30 years. In the past, scientists have thought of EVs as cellular dust. Today, EVs are thought to be carriers of intercellular biological information, as they may contain nucleic acids, lipids, and proteins, thereby playing an indispensable role in cell-to-cell communication. ${ }^{9} \quad$ Furthermore, the composition of EVs varies according to their origin, and the information they carry also varies. $^{10}$ Biological characteristics and functions of EVs suggest their potential application for cell-free regeneration strategies, which may avoid the disadvantages of current stem cell transplantation techniques.

Therapeutic angiogenesis via cellular transplantation has been proposed to serve as an effective and promising alternative therapy for the treatment of patients with severe limb ischemia who have no other option for revascularization. ${ }^{11-19}$

Therapeutic angiogenesis has been introduced in recent years as an alternative for limb salvage in patients with occluded peripheral arteries, based on the concept that formation of new vessels is possible via vasculogenesis, angiogenesis, and arteriogenesis, and these new vessels would be able to replace the function of the occluded arteries and to ensure an adequate supply of oxygen in severely ischemic tissues. $^{20-24}$

Vasculogenesis and angiogenesis are complex processes that lead to the formation of new capillaries, being controlled by numerous soluble growth factors, inhibitors, cytokines, adhesion molecules, and extracellular matrix proteins. The main difference between the two processes relies in the mechanism of formation of capillaries. While vasculogenesis refers to in situ assembly of precursor cells into capillaries, angiogenesis represents the formation of new capillaries from preexisting vessels. ${ }^{24-27}$ Arteriogenesis is another complex process of vessel formation, which is fundamentally based on collateralization. Preexisting collateral vessels can enlarge up to 25 times their original size to facilitate increase in blood supply. ${ }^{28}$

Arteriogenesis is associated with structural remodeling of the vessel and significant increase in the endoluminal shear stress, which in turn activates endothelial cells and triggers the release of factors that recruit monocytes to collaterals. ${ }^{28}$

After the first description by Asahara, in 1997, of the potential of cells originating from the bone marrow (BM) to differentiate into endothelial cells, promote vessel growth, and stimulate vasculogenesis, many attempts have been made in order to validate these cells as a therapeutic agent. $^{29}$ The concept of cell therapy in limb ischemia is based on the capacity of the bone marrow-derived progenitor cells to promote collateral vessel formation and neovascularization of ischemic tissue. ${ }^{30}$

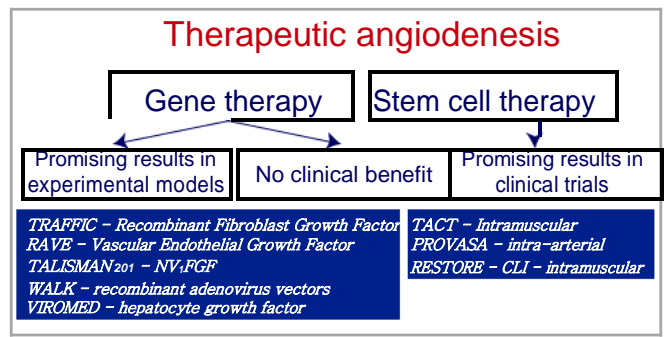

Figure 1. Stages in angiogenesis

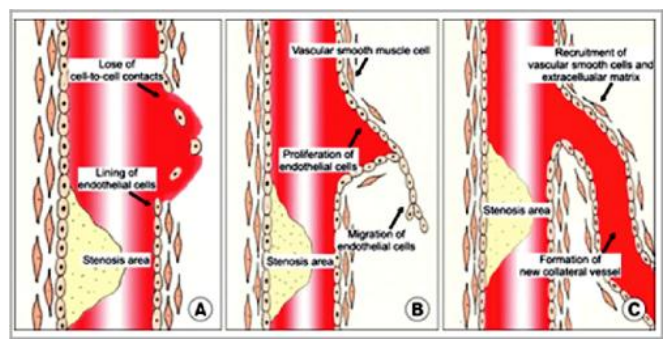

Figure 2. Therapeutic angiogenesis with stem cell 


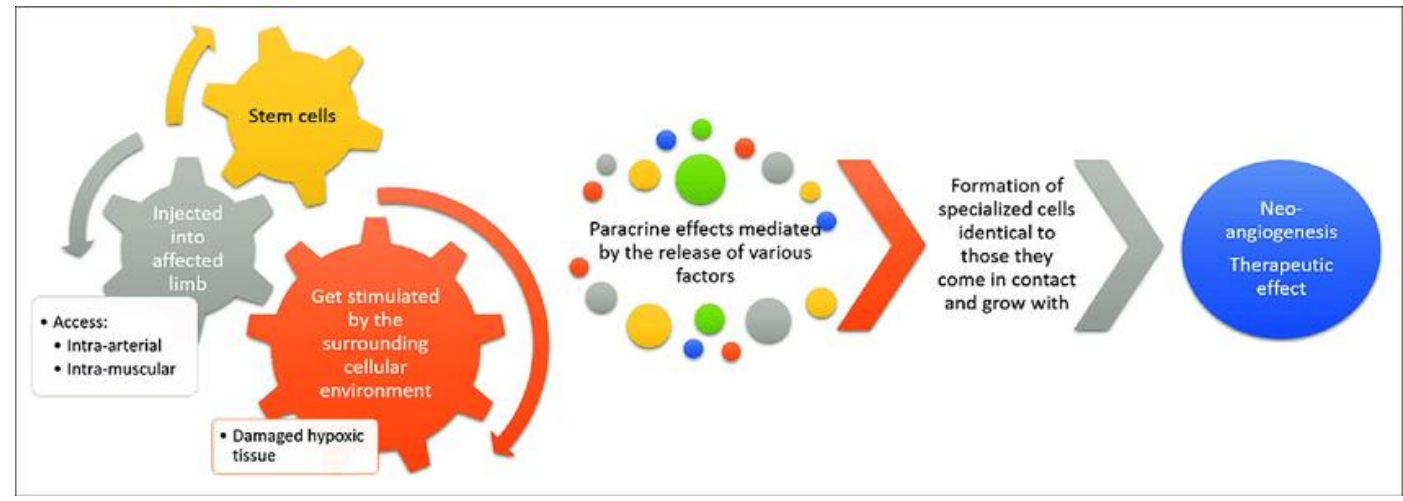

Figure 3: Mechanisms of angiogenesis

Hypoxia is the most important triggering factor that affects the initiation of angiogenesis. Oxygen tension plays a major role in the expression of numerous genes such as the vascular endothelial growth factor (VEGF) family and proangiogenic growth factor. $^{31}$ In addition, hypoxia stimulates the transcription of promoter genes and this is mediated by the activation of hypoxia-inducible farctor-1 (HIF-1) and it leads to increased VEGF. The key steps during angiogenesis are summarized as endothelial activation, migration, proliferation and reorganization. ${ }^{31}$ These steps are strictly regulated by proand anti-angiogenic factors. VEGF is derived from platelets and it is a specific mitogen for endothelial cells and it is induced by hypoxia via HIF-1. It binds with tryrosine-kinase receptors, and then it stimulates not only endothelial proliferation and differentiation, but also increased endothelial permeability. Other growth factors such as TGF-B, FGF or PDGF also increase the expression of VEGF, and inhibitory factors such as angiostatin decrease the VEGF expression.

\section{Case Report}

Mr. Khalil age 55 years old man diabetic, hypertensive came to Sure cell Medical (BD) Ltd. with complains of pain and blackening of left ring finger tip for 5 weeks and pain along the ulnar border of the left upper limb for 3 months. He smoked a pack a day for the last 30 years. On past medical treatment history he took oral hypoglycemic, beta-blocker, aspirin and vasodilator drugs. On general examination of patient was mildly anaemic non icteric, all vital organ were in normal range. Systemic Examination revealed no abnormalities detected. Local Examination of left ring finger showed dry gangrene of tip $1.5 \times 1 \mathrm{~cm}$, dusky distal third, absent ulnar arterial pulse, normal sensation. Peripheral arterial pulse of posterior tibial of both lower limbs were absent. He had normal total and differential white cell counts and platelet counts, uncontrolled diabetes (HbA1C: 11.5\%, Fasting Blood Sugar: $12.5 \mathrm{mmol} / \mathrm{L}$, Blood Sugar $2 \mathrm{Hrs}$ ABF: $18.6 \mathrm{mmol} / \mathrm{L})$, serum creatinine $1.4 \mathrm{mg} / \mathrm{dl}$, chest X-ray, ECG, echocardiogram reports were normal. Peripheral angiography upper limb vessels showed left and right ulnar arteries are $100 \%$ occluded from mid part. Digital vessels of left ring finger were not visualized. He was advised for amputation of the left ring finger at middle phalanx level in BIRDEM OPD. He did not comply and went to vascular surgeon who did a peripheral angiogram. Vascular surgeon referred the patient to a stem cell therapy centre. At the centre re-evaluation of patient was done and found dry gangrene of left ring finger tip for 5 weeks, relatively colder left ring finger for 4 weeks and cramping pain along ulnar border of upper limb even at rest causing sleep disturbance for three months and diagnosed a case of ischemic gangrene of left ring finger tip with diabetes mellitus with hypertension with peripheral vascular disease. Patient was selected for stem cell therapy after proper counseling. 
He received the therapy in the form of SVF (Stromal Vascular Fraction) from adipose tissue by local injection in the territory of the affected vessels. Following monitoring parameters were reported: wound status, local temperature change, oxygen saturation change in the ischemic zone.

Outcome of stem cell therapy in this case: the rest pain disappeared at 14 days and the finger becomes warmed by $5^{\circ} \mathrm{C}$ in 3 weeks. The gangrenous area healed in 3 months. Amputation was averted.

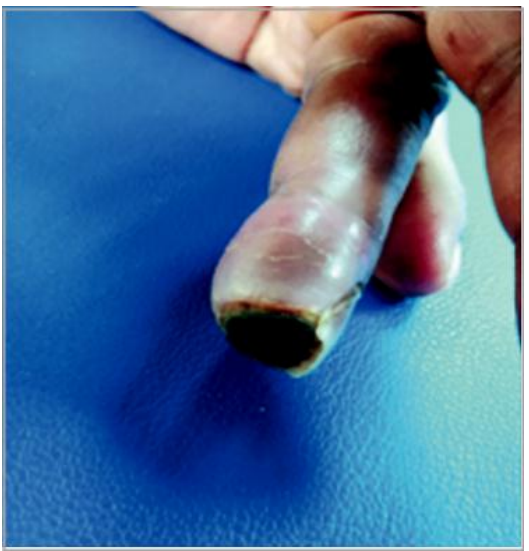

Figure 4: Dry gangrene of left ring finger tip

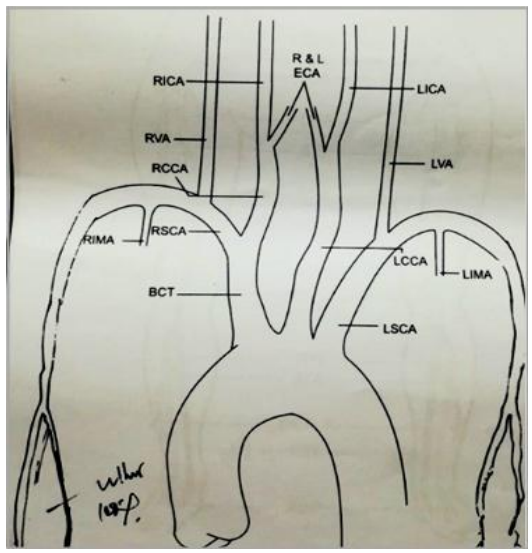

Figure 5: Four vessels angiogram showed left and right ulnar arteries are $100 \%$ occluded from mid part. Digital vessels of left ring finger were not visualized.

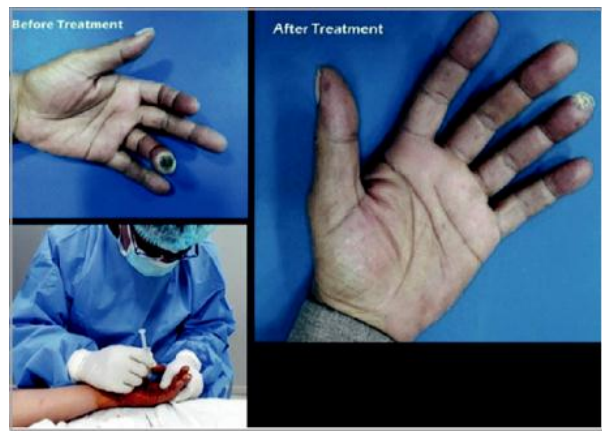

Figure 6: Before and after treatment, gangrenous area healed in $\mathbf{3}$ months.

Take home message: We do not need to go for immediate excision when we see a dry gangrenous area. We can wait and keep the patient in regular follow up after proper counseling. Stem Cell therapy is an option to be considered for ischemic limbs before going for amputation

\section{Discussion}

Stem cells are defined as undifferentiated cells that are capable of self-renewal and differentiation into the specialized cells through their replication. ${ }^{32}$ In order for any of the cells that are isolated from peripheral blood, bone marrow etc. to be defined as stem cells, it must be proved that the cells differentiate or transform into specific cells or tissue under specific conditions.

There are three recent revolutionary discoveries for stem cells that have demonstrates stem cells' clinical potential in a variety of diseases. ${ }^{33}$ First, stem cells have been discovered in organs that were previously thought to lack regenerative potential. Second, organ-specific adult stem cells exhibit much more plasticity than we originally thought. This fact means that stem cells derived from one type of cell or tissue can differentiate into unrelated types of tissue. So, it had been proposed that the use of adult stem cells should be considered as a treatment strategy for diseases that require vascular regeneration. Third, embryonic stem cells can be isolated and differentiated into a variety of cell types in vitro. So, their differentiation ability may hold promise for the treatment of many types of 
disease that require tissue repair, such as stroke, neuro-degenerative disease and myocardial infarction.

Stem cells can be divided into two types, that is, embryonic and adult stem cells. Embryonic stem cells are derived from the fetus that is in the blastocyst stage and these cells have various abilities to differentiate into multiple cellular lineages. However, there are some problems with using embryonic stem cells in the clinical field because these cells tend to develop into tumors such as teratoma, and most of all, the ethical controversies for their procurement and use remain to be solved. In contrast, adult stem cells are distributed throughout the body and they have the potential to differentiate into specific tissue under certain circumstances, but this potential is quiescent under normal physiologic conditions. Although adult stem cells are distributed throughout the body, there are tissue-specific locations for each type of stem cell. For example, hematopoietic and mesenchymal stem cells are primarily located in bone marrow and peripheral bloodneural stem cells are located in ependymal cells and astrocytes, and skeletal-muscle stem cells are located in muscle fiber. ${ }^{34-36}$

In most clinical trials, peripheral blood, bone marrow, cord blood or placenta have been used as the sources of stem cells because these tissues have a rich content of stem cells and the cells are easily and safely harvested for isolation. ${ }^{37}$

Several experimental studies have reported that purified stem cells are able to generate cardiomyocytes and vascular structures. ${ }^{38,39}$

The exact mechanisms of angiogenesis by stem cells in various ischemic vascular diseases are poorly understood. It is thought that stem cells may cause the release of a variety of angiogenic factors such as VEGF and $\mathrm{bFGF}$, and these factors mediate a paracrine effect into the ischemic lesion, and as a result, angiogenesis is triggered.

In addition, some studies have reported serious adverse events, including myocardial infarctions, in-stent stenosis and arteriovenous fistula. ${ }^{40-42}$ There are several possible mechanisms for these adverse events. ${ }^{43}$ First, controlling the migration of stem cells into lesion sites may modify the risk and benefit of stem cell therapy. Second, the differentiation of stem cells may not be as directed as we have desired. As a result, acceleration of new arterial plaque or plaque instability has been demonstrated.

\section{Conclusions}

In conclusion, most of the previous clinical trials have reported that stem cell therapy could serve as a novel therapeutic modality for patients with peripheral arterial disease (PAD). However, there are several limitations to directly apply stem cell therapy in the clinical field. First, the mechanisms of angiogenesis by administration of stem cells have not been yet proven. Second, most of the trials have had a small number of subjects, a variety of inclusion criteria and they were non-randomized trials. Third, there has been the lack of standard reporting for the outcomes, adverse events and safety. Fourth, the most effective type of stem cells, the timing of administration, the amount and the route of administration that causes angiogenesis in patients with PAD have not been established.

Therefore, multicenter, large-scale and randomized controlled clinical trials may be fundamental and mandatory to prove the safety and efficacy of promoting angiogenesis by the administration of stem cells and for this therapy to become a standard treatment strategy for the patients suffering with PAD.

\section{References:}

1. Pande $R L$, et al. A pooled analysis of the durability and predictors of treatment response of cilostazol in patients with intermittent claudication. Vasc Med. 2010;15:181-8.

2. Mellière $D$, et al. The underestimated advantages of iliofemoral endarterectomy. Ann Vasc Surg. 2000;14:343-9. 
3. Trams EG, et al. Exfoliation of membrane ectoenzymes in the form of micro-vesicles. Biochim Biophys Acta. 1981;645:63-70.

4. Wu R, et al. Drug-eluting balloon versus standard percutaneous transluminal angioplasty in infrapopliteal arterial disease: a meta-analysis of randomized trials. Int $J$ Surg. 2016;35:88-94.

5. Li S, et al. Advances in the treatment of ischemic diseases by mesenchymal stem cells. Stem Cells Int. 2016;2016:5896061.

6. Choi $M$, et al. Proangiogenic features of Wharton's jelly-derived mesenchymal stromal/stem cells and their ability to form functional vessels. Int $J$ Biochem Cell Biol. 2013;45:560-70.

7. Fouraschen SM, et al. Secreted factors of human liver-derived mesenchymal stem cells promote liver regeneration early after partial hepatectomy. Stem Cells Dev. 2012;21:2410-9.

8. Ionescu L, et al. Stem cell conditioned medium improves acute lung injury in mice: in vivo evidence for stem cell paracrine action. Am J Physiol Lung Cell Mol Physiol. 2012;303:L967-77.

9. Panfoli $I$, et al. Microvesicles as promising biological tools for diagnosis and therapy. Expert Rev Proteomics. 2018;15:801-8.

10. Muralidharan-Chari $V$, et al. Microvesicles: mediators of extracellular communication during cancer progression. $J$ Cell Sci. 2010;123:1603-11.

11. Qadura M, Terenzi DC, Verma S, Al-Omran $M$, Hess DA. Cell Therapy for Critical Limb Ischemia: An Integrated Review of Pre- clinical and Clinical Studies. Stem Cells. 2017; doi: 10.1002/stem.2751.

12. Pignon $B$, Sevestre $M A$, Kanagaratnam $L$, et al. Autologous Bone Marrow Mononuclear Cell Implantation and Its Impact on the Outcome of Patients With Critical Limb Ischemia - Results of a Randomized, Double-Blind, PlaceboControlled Trial. Circ J. 2017;81:1713-1720.

13. Ismail AM, Abdou SM, Aty HA, et al. Autologous transplantation of CD34(+) bone marrow derived mononuclear cells in management of non-reconstructable critical lower limb ischemia. Cytotechnology. 2016;68:771-781.
14. Perotti $C$, Arici V, Cervio $M$, et al. Allogeneic lethally irradiated cord blood mononuclear cells in no-option critical limb ischemia: a "box of rain". Stem Cells Dev. 2013;22:2806-2812.

15. Liew A, O'Brien $T$. Therapeutic potential for mesenchymal stem cell transplantation in critical limb ischemia. Stem Cell Res Ther. 2012;3:28.1.

16. Koshikawa M, Shimodaira S, Yoshioka T, et al. Therapeutic angiogenesis by bone marrow implantation for critical hand ischemia in patients with peripheral arterial disease: a pilot study. Curr Med Res Opin. 2006;22:793-798.

17. Hernández P1, Cortina L, Artaza $H$, et al. Autologous bone- marrow mononuclear cell implantation in patients with severe lower limb ischaemia: a comparison of using blood cell separator and Ficoll density gradient centrifugation.Atherosclerosis.2007;194:e5256 .

18. Lachmann N, Nikol S. Therapeutic angiogenesis for peripheral artery disease: stem cell therapy. Vasa. 2007;36:241-251.

19. Napoli C, Farzati B, Sica V, et al. Beneficial effects of autologous bone marrow cell infusion and antioxidants/L- arginine in patients with chronic critical limb ischemia. Eur J Cardiovasc Prev Rehabil. 2008;15:709-718.

20. Risau W. Mechanisms of angiogenesis. Nature. 1997;386:671- 674

21. Ouma GO, Zafrir B, Mohler ER 3rd, Flugelman $M Y$. Therapeutic angiogenesis in critical limb ischemia.Angiology.2013;64:466-480.

22. Annex BH. Therapeutic angiogenesis for critical limb ischaemia. Nat Rev Cardiol. 2013;10:387396.

23. Carmeliet P. Mechanisms of angiogenesis and arteriogenesis. Nat Med. 2000;6:389-395.

24. Davies MG. Criticial Limb Ischemia: Epidemiology. Methodist DeBakey Cardiovascular Journal. 2012;8:10-14.

25. Ribatti $D$, Vacca $A$, Nico $B$, Presta $M$, Roncali L. Angiogenesis: basic and clinical aspects. Ital J Anat Embryol. 2003;108:1-24.38 
26. Semenza GL. Vasculogenesis, angiogenesis, and arteriogenesis: mechanisms of blood vessel formation and remodeling. J Cell Biochem. 2007; 102:840-847.

27. Axnick J, Lammert E. Vascular lumen formation. Curr Opin Hematol. 2012;19:192 198.1.

28. Zhu S, Liu $X$, Li $Y$, Goldschmidt-Clermont PJ, Dong $C$. Aging in the atherosclerosis milieu may accelerate the consumption of bone marrow endothelial progenitor cells. Arterioscler Thromb Vasc Biol. 2007;27:113-119.

29. Asahara $T$, Murohara $T$, Sullivan $A$, et al. Isolation of putative progenitor endothelial cells for angiogenesis. Science. 1997;275:964-967.

30. Gupta R, Losordo DW. Cell Therapy for Critical Limb Ischemia Moving Forward One Step at a Time. Circ Cardiovasc Interv. 2011;4:2-5.

31. Collinson DJ, Donnelly $R$. Therapeutic anigogenesis in peripheral arterial disease: can biotechnology produce an effective collateral circulation? Eur J Vasc Endovasc Surg. 2004;25:9-23.

32. Burt RK, Loh Y, Pearce W, Beohar N, Barr WG, Craig R, Wen Y, Rapp JA, Kessler J. Clinical applications of blood-derived and morrowderived stem cells for nonmalignant disease. JAMA. 2008;299:925-936.

33. Kaji EH, Leiden JM. Gene and stem cell therapies. JAMA. 2001;285:545-550.

34. Ko IK, Kim BS. Mesenchymal stem cells for treatment of myocardial infarction. International J Stem Cells. 2008;1:49-54.

35. Kim SU, Lee HJ, Park IH, Chu K, Lee ST, Kim $\mathrm{NH}$, Roh JK, Kim SK, Wang KC. Human neural stem cells for brain repair. International J Stem Cells. 2008;1:27-35.

36. Korbling M, Estrov Z. Adult stem cells for tissue repair-a new therapeutic concept? $N$ Engl $J$ Med. 2003;349:570-582 .

37. Lee KB, Kim AK, Kim MJ, Do YS, Shin SW, Kim JS, Park CJ, Kang KS, Kim BS, Joh JH, Oh WI, Hong HK, Kim DI. Angiogenesis induced by autologous whole bone marrow stem cells transplantation. International J Stem Cells. 2008;1:64-69.1.
38. Orlic D, Kajstura J, Chimenti S, Jakoniuk I, Anderson SM, Li B, Pickel J, McKay R, NadalGinard B, Bodin DM, Leri A, Anversa $P$, Bone marrow cells regenerate infarcted myocardium. Nature. 2001;410:701-705.

39. Jackson KA, Majka SM, Wang $H$, Pocius J, Hartley CJ, Majesky MW, Entam ML, Michael $L H$, Hirschi KK, Goo-dell MA. Regeneration of ischemic cardiac muscle and vascular endothelium by adult stem cells. J Clin Invest. 2001;107:1395-1402.

40. Tateishi-Yuyama E, Matsubara $H$, Murohara $T$, Ikeda U, Shintani S, Masaki H, Amano K, Kishimoto $Y$, Yoshimoto K, Akashi H, Shimada $K$, Iwasaka $T$, Imaizumi $T$. Therapeutic angiogenesis for patients with limb ischemia by autologous transplantation of bone marrow cells: a pilot study and a randomized controlled trial. Lancet. 2002;360:427-435.

41. Kang HJ, Kim HS, Zhang SY, Park KW, Cho HJ, Koo BK, Kim YJ, Lee DS, Sohn DW, Han KS, Oh BH, Lee MM, Park YB. Effects of intracoronary infusion of peripheral blood stem cells mobilized with granulocyte-colony stimulating factor on left ventricular systolic function and restenosis after coronary stenting in myocardial infarction: the MAGIC cell randomized clinical trial. Lancet.2004;363:751756.

42. Miyamoto K, Nishigami K, Nagaya N, Akutsu K, Chiku M, Soma T, Miyata Sm, Higashi M, Tanaka $R$, Nakatani T, Nonogi H, Takeshita S. Unblinded pilot study of autologous transplantation of bone marrow mononuclear cells in patients with thromboangiitis obliterans. Circulation. 2006;114:2679-2684.

43. Hirsch AT. Critical limb ischemia and stem cell research: informed adverse event reporting anchoring hope with informed adverse event reporting. Circulation. 2006;114:2581-2583.1.1. 